\title{
Effect of Lactobacillus Plantarum on the Growth and Development and Gut Microbial Diversity of Spodoptera Litura
}

\section{Zijie Ma}

South China Agricultural University

\section{Xiao-Fan Wang}

South China Agricultural University

\section{Ming-Wei Li}

South China Agricultural University

\section{Li-Ping Nie}

South China Agricultural University

Wan-Ting Zhang

South China Agricultural University

Meide Liao ( $\square$ liaomeide@scau.edu.cn )

South China Agricultural University https://orcid.org/0000-0002-9651-8589

\section{Research Article}

Keywords: Spodoptera litura, Lactobacillus plantarum, enzyme activity, nutritional physiology, gut microflora

Posted Date: June 7th, 2021

DOl: https://doi.org/10.21203/rs.3.rs-571762/v1

License: (9) This work is licensed under a Creative Commons Attribution 4.0 International License. Read Full License 


\section{Code availability}


$4 \quad$ Not applicable.

5

6

We would like to thank Editage (www.editage.cn) for English language editing. 


\title{
Effect of Lactobacillus plantarum on the growth and
}

\section{development and gut microbial diversity of Spodoptera litura}

\author{
Zijie Ma, Xiao-Fan Wang, Ming-Wei Li , Li-Ping Nie, Wan-Ting Zhang, Meide Liao*
}

(Department of Pesticide, College of Plant Protection, South China Agricultural University, Guangzhou 510642， China)

\begin{abstract}
Background: The main challenge for agricultural research is the determination of the best method for efficient and economical management of insects. Research on the possibility of regulating insect development by targeting the intestinal microbial community is in its early stages; however, the use of microorganisms to control the composition of the host's intestinal microbes and to affect its physiological functions has garnered considerable attention.
\end{abstract}

Results: This study evaluated the effects of probiotics (Lactobacillus plantarum) isolated from the intestine of Spodoptera litura (Fabricius) on the growth and development of the host and the diversity of its intestinal microbes. The results of the study showed that the larvae of S. litura fed with artificial diets with different feed units could proceed towards the development of generations normally. Compared with the control responses, after ingesting L. plantarum, larval gut sucrase and other digestive enzyme activities increased, growth and development accelerated, fecundity generally increased, and there was a significant change in the female-male ratio. Additionally, differences in

* Author for correspondence Meide Liao, Department of Pesticide Associate Professor, College of Plant Protection, South China Agricultural University, Guangzhou 510642, China.

cell-phone number: 86-13610008987

E-mail: liaomeide@scau.edu.cn 
1

2

microbial abundance and diversity were found in the gut of S. litura larvae fed with diets supplemented with L. plantarum and without $L$. plantarum.

Conclusions: These findings indicate that supplementation of feed with L. plantarum can effectively affect the growth and development of the host and the composition of the intestinal flora, thereby providing useful applications in research regarding pest management.

Keywords: Spodoptera litura, Lactobacillus plantarum, enzyme activity, nutritional physiology, gut microflora

There are several types of insects with different morphologies, and insects are the most widely distributed animal group in the world. Insect gut microbes are an important part of the symbiotic system of insects and microbes formed during their long-term co-evolution (Paniagua Voirol 2018), and they play an irreplaceable role in the evolution of insect diversity and the adaptability of the host environment. Limited by the difficulty of separating and cultivating insect intestinal flora in vitro, the diversity of insect intestinal microorganisms and related research continues to progress slowly; however, in recent years, with the widespread application of $16 \mathrm{~S}$ high-throughput sequencing in insect research, a better understanding of the diversity of insect gut microbiota has been achieved. Multiple studies have shown that insect gut microbes are crucial to the development, digestion, metabolism, reproduction, immunity, and several physiological functions of their host (Li 2020). Studies have shown that Burkholderia (Yabuuchi et al., 1993), a commensal bacterium that inhabits the intestinal tract of stink bugs Leptocorisa chinensis (Dall, 1852), confers resistance to the host against pyridoxine (Kikuchi 2011, 2012), and the Drosophila melanogaster (Meigen, 1830) endosymbiont, Wolbachia 
1 (Hertig, 1936), can effectively inhibit the infection of the host by Drosophila C virus (DCV) (Hedges

2 2008; Teixeira 2008). Moreover, symbiotic bacteria in the intestine of the desert migratory locust

3 Schistocerca gregaria (Forskl, 1775), Pantoea agglomerans (Ewing and Fife, 1972), can synthesize

4 pheromones such as guaiacol, thereby regulating population behavior (Dillon 2002). The fact that

5 endogenous bacteria may affect the healthy development and nutrient absorption of the larvae of

6 Hepialus gonggaensis (Fu et Huang, 1991) further hints at the importance of intestinal flora in the

7 environmental adaptation of insect hosts (Yin 2011). Since insect gut microbes are major players in

8 host nutrition and health, the potential manipulation of microbial communities has attracted the interest

9 of several scholars, and studies have shown that the composition of insect intestinal flora is easily altered by the host environment and dietary composition (Hammer 2015). Therefore, this plasticity provides the possibility of using probiotics to manipulate insect intestinal flora for specific investigation. Evans manipulated the Italian bee diet with lactic acid bacteria to regulate the homeostasis of intestinal microbes, effectively promoting the host's internal immune response to resist the invasion of pathogenic bacteria (Evans 2006).

Currently, research regarding the possibility of regulating insect development by targeting the intestinal microbial community is in early stages; however, such an approach may be helpful in the development of an adequate method for the efficient and economical management of insects. Thus far, the widespread application of antibiotics and chemical pesticides in insect management has shown effectiveness in curbing the spread of pests and insect-borne diseases to a certain extent; however, issues such as insect resistance have compelled researchers to explore new solutions in insect management. Subsequently, the application of microorganisms to manage pests has garnered considerable attention from scholars at home and abroad. Among them, Metarhizium anisopliae 
1 [Metschn.(1879) Sorokin, 1883] (Fite 2020; Mkiga 2020), Bacillus thuringiensis (Berliner, 1911)

(Fite 2020; Heckel 2020), Wolbachia (Hertig, 1936) (Poinsot 2003; Crawford 2020), Bacillus subtilis

[Ehrenberg.(1835) Cohn, 1872] (Fouda 2001), and other microorganisms have been the focus of extensive research regarding their application in insect management; however, research on endogenous probiotics and their regulation of host intestinal microbes has been less comprehensive. Additionally, although biological control and sterile insect technologies have contributed to certain achievements in insect management, they are insufficient; therefore, the use of probiotics to manipulate the composition of intestinal microbes to achieve ecological control of the host may be a potential supplement to these existing technologies and other insect management methods. Considering the manipulability of probiotics on the intestinal flora, we used the endogenous probiotic L. plantarum that is found in the intestine of $S$. litura, to regulate the composition of the host intestinal microbial community to varying degrees, and explored the influence of L. plantarum on the intestinal microbial diversity, growth, and development of $S$. litura under laboratory conditions. As a major pest, S. litura has been widely used in various studies; however, because large-scale breeding of $S$. litura is mainly conducted using approaches that include the provision of artificial diets, this study aimed to evaluate the influence of L. plantarum on the growth, development, and intestinal microbial diversity of S. litura fed with an artificial diet, to provide a theoretical reference for the subsequent screening of insect-specific microecological agents and biological controls.

\section{Methods}

\section{Insect culture}


1 Biology of the Ministry of Education, P. R. China. The larvae were reared on an artificial diet as per

2 methods recommended by Zhu et al. (2001) with slight modifications for subsequent generations, and under controlled temperature and humidity conditions of $26 \pm 2{ }^{\circ} \mathrm{C}$ and $80 \% \pm 5 \%$, respectively. The main ingredients of the artificial diet were organic corn flour, cooked soy flour, nine vitamin pills, methyl-p-hydroxybenzoate, sorbic acid, and cholesterol. The rearing was performed in a transparent plastic box $\left(17 \times 11.5 \times 6 \mathrm{~cm}^{3}\right)$ with daily changes in diet. The mature larvae were placed in a ten-well plate for pupation. After the pupae were collected, they were placed in a transparent plastic box in which the bottom portion was moistened with wet filter paper. Freshly emerged adults were transferred to transparent plastic buckets $\left(22 \times 28 \times 26 \mathrm{~cm}^{3}\right)$ containing $10 \%$ honey water at the bottom to prepare the adults for laying eggs. The transparent plastic buckets were lined with butter paper to facilitate egg laying. Larvae from the fourth generation of laboratory cultures were used for experimental purposes.

\section{Bioassay studies}

The artificial diet of S. litura was supplemented with L. plantarum (GenBank accession number: MW174226), and suspensions were used to prepare diets with different unit feed bacterial loads, including $1.9 \times 10^{7} \mathrm{CFU} / \mathrm{g}$ (hereafter referred to as CD7), $1.9 \times 10^{6} \mathrm{CFU} / \mathrm{g}$ (hereafter referred to as CD6), $1.9 \times 10^{5} \mathrm{CFU} / \mathrm{g}$ (hereafter referred to as CD5), and $1.9 \times 10^{4} \mathrm{CFU} / \mathrm{g}$ (hereafter referred to as CD4). A diet without L. plantarum served as a control (CK). Experiments were performed with 60 first-instar larvae with three replicates (20 larvae per replicate) for each treatment group. The experiments were conducted at $26 \pm 2{ }^{\circ} \mathrm{C}$ temperature, $80 \% \pm 5 \%$ relative humidity, and a photoperiod of 16:8 h (L:D).

Observations were performed daily on various biological parameters of S. litura, including single female egg production, egg hatching rate, sex ratio, percent pupation, and adult emergence. 


\section{Determination of nutritional index of larvae}

The larvae of S. litura that underwent molting to transition into the fourth-instar stage and showed consistent healthy development during which they were fed with artificial diets with different bacterial loads, were subjected to starvation overnight.

1) Twenty S. litura larvae reared on artificial diets with different bacterial loads (including the control group) were selected, and their fresh weight was recorded; then, they were subjected to drying conditions in an oven at $80{ }^{\circ} \mathrm{C}$ to achieve a constant weight, and the dry-wet ratio was determined.

2) Twenty larvae were selected and their fresh weight was recorded. According to the dry-wet ratio of the tested larvae, the dry weight of the larvae before the test (C) was inferred, and then they were fed with artificial feed with different bacterial loads (including the control group). After $48 \mathrm{~h}$, the residual feed and feces were removed, and the larvae and feces were subjected to drying conditions at $80{ }^{\circ} \mathrm{C}$ to achieve a constant weight to determine the dry weight of the feces (E) and the dry weight of the larvae (D).

3) Based on the same method as that mentioned above, the dry weight of feed with different bacterial loads was measured before (A) and after (B) execution of the tests.

Nutritional indices were calculated as per methods prescribed by Wheeler \& Isman (2001) using the following formulae:

Relative growth rate $(R G R)=\frac{D-C}{[(D+C) / 2] \times T}$

Relative consumption rate $(R C R)=\frac{A-B}{[(C+D) / 2] \times T}$

Approximate digestibil ity $(A D)=\frac{A-B-E}{A-B}$ 
1 Efficiency of conversion of ingested food $(E C I)=\frac{D-C}{A-B}$

2 Efficiency of conversion of digested food $(E C D)=\frac{D-C}{A-B-E}$

3 In the formula, $\mathrm{T}$ represents the number of experimental days.

4 Each treatment contained 20 larvae, with 3 replicates.

\section{Determination of digestive enzyme activity in the larval midgut}

The intestinal crude enzyme solution was prepared according to the method described by Wang et al. (2016). Additionally, amylase, trehalase, and sucrase activities were determined according to the method described by Wang et al. (2016).

\section{6s high-throughput sequencing of the gut bacteria of $S$. litura}

Spodoptera litura fed with a diet supplemented with L. plantarum and without L. plantarum, and twenty healthy and well-developed fourth-instar larvae were randomly selected; they were subjected to starvation for $24 \mathrm{~h}$, and placed on a sterile ultra-clean workbench. The dissecting instrument was sterilized in an autoclave before commencement of the experiments. The body surface of the S. litura were submerged in $75 \%$ alcohol for $300 \mathrm{~s}$. After rinsing with sterile distilled water, the intestines of the S. litura larvae were dissected under aseptic conditions. The collected samples were mixed in distilled water and sent to Beijing Kinco Biotechnology Co., Ltd. for sequencing.

\section{Statistical analysis}

The SPSS software (version 22.0; SPSS Inc., Chicago) was used for performing one-way analysis 


\title{
Results
}

\section{Nutritional effect of artificial diets with different bacterial loads exerted on}

\author{
fourth-instar larvae
}

As shown in Table 1, the relative feeding rates of the different larval feeding groups were in the order CD6 $>\mathrm{CK} \geq \mathrm{CD} 4>\mathrm{CD} 5>\mathrm{CD}$ 7. There was a significant difference between rates of the CD6 group and the $\mathrm{CD} 7$ group, and there was no significant difference between the other groups. The relative food conversion rates of the larval groups were in the order CD6 $>$ CD5 $>$ CD7 $>$ CK $>$ CD4 . The food conversion rate of the CD6 group was significantly higher than that of the other groups, and the food conversion rates of the larvae in the other groups were not significantly different from those of the CK group. The relative food utilization rates of the different larval groups were in the order CD6 > $\mathrm{CD} 7 \geq \mathrm{CD} 5 \geq \mathrm{CK}>\mathrm{CD}$ 4. There was no significant difference between the food utilization rates of the bacteria-fed larval groups and the control; however, the food utilization rate of the CD6 group was significantly higher than that of the $\mathrm{CD} 7$ and $\mathrm{CD} 4$ groups. The relative growth rates of the larval groups were in the order $\mathrm{CD} 6 \geq \mathrm{CK}>\mathrm{CD} 5>\mathrm{CD} 4>\mathrm{CD} 7$, and relative growth rates of the $\mathrm{CD} 6$ group were significantly higher than those of the other bacteria-fed groups; however, none of the bacteria-fed groups exhibited a significant difference compared with the control group. The relative approximate digestibility of the larval groups were in the order $\mathrm{CK}>\mathrm{CD} 4>\mathrm{CD} 5>\mathrm{CD} 7>\mathrm{CD} 6$, and that of the CD6 group was significantly lower than that of the control group. 


\begin{tabular}{|c|c|c|c|c|c|c|}
\hline Nutrition index & $\mathrm{CK}$ & CD4 & CD5 & CD6 & $\mathrm{CD} 7$ & \\
\hline $\begin{array}{l}\text { (RCR) } \\
\text { Relative feeding rate of larvae }\end{array}$ & $\begin{array}{l}2.77 \pm \\
0.64 \mathrm{ab}\end{array}$ & $\begin{array}{l}2.77 \pm \\
0.13 \mathrm{ab}\end{array}$ & $\begin{array}{l}2.24 \pm \\
0.34 \mathrm{ab}\end{array}$ & $2.95 \pm 0.22 \mathrm{a}$ & $2.13 \pm 0.30 \mathrm{~b}$ & $\mathrm{p} \leqslant 0.05$ \\
\hline $\begin{array}{c}\text { Efficiency of conversion of } \\
\text { digested food }\end{array}$ & $\begin{array}{l}0.51 \pm \\
0.08 \mathrm{bc}\end{array}$ & $0.42 \pm 0.05 c$ & $0.60 \pm 0.15 b$ & $0.80 \pm 0.06 a$ & $0.58 \pm 0.06 b c$ & $\begin{array}{l}F=7.393, \\
p \leqslant 0.05\end{array}$ \\
\hline $\begin{array}{c}\text { Efficiency of conversion of } \\
\text { ingested food }\end{array}$ & $\begin{array}{l}0.18 \pm \\
0.01 \mathrm{ab}\end{array}$ & $0.15 \pm 0.04 b$ & $\begin{array}{l}0.18 \pm \\
0.03 \mathrm{ab}\end{array}$ & $0.24 \pm 0.02 \mathrm{a}$ & $0.18 \pm 0.04 b$ & $\begin{array}{c}\mathrm{F}=3.447, \\
\mathrm{p} \leqslant 0.05\end{array}$ \\
\hline Relative growth rate & $\begin{array}{l}0.54 \pm \\
0.05 \mathrm{ab}\end{array}$ & $0.41 \pm 0.12 b$ & $0.42 \pm 0.06 b$ & $0.62 \pm 0.04 \mathrm{a}$ & $0.38 \pm 0.14 b$ & $\begin{array}{c}\mathrm{F}=3.751, \\
\mathrm{p} \leqslant 0.05\end{array}$ \\
\hline Approximate digestibility & $0.37 \pm 0.04 \mathrm{a}$ & $\begin{array}{l}0.36 \pm \\
0.08 \mathrm{ab}\end{array}$ & $\begin{array}{l}0.32 \pm \\
0.02 \mathrm{ab}\end{array}$ & $0.27 \pm 0.02 b$ & $0.30 \pm 0.04 \mathrm{ab}$ & $\mathrm{p} \leqslant 0.05$ \\
\hline
\end{tabular}

Note: The values in the table represent mean \pm standard deviation. Different letters in the same row indicate significant differences

$3(\mathrm{P}<0.05)$ as tested by using Duncan's new multiple range test. $\mathrm{CD} 4-\mathrm{CD} 7$ : four treatment groups fed with an artificial diet with different

4 bacterial loads; CK: control group.

5

As shown in Table 2, the average fresh weights of the larvae fed with artificial diets containing different bacterial loads were in the order CD6 > CD7 > CK > CD4 $\geq$ CD5, and those of the CD4

8 group and CD5 group were significantly lower than those of the CD6 group; however, none of

9 bacteria-fed groups presented a significant differences compared with the control group. 


\begin{tabular}{cc}
\hline The sample name & Average weight \\
\hline CD7 & $0.57 \pm 0.07 \mathrm{ab}$ \\
CD6 & $0.61 \pm 0.02 \mathrm{a}$ \\
CD5 & $0.52 \pm 0.02 \mathrm{~b}$ \\
CD4 & $0.52 \pm 0.07 \mathrm{~b}$ \\
CK & $0.56 \pm 0.02 \mathrm{ab}$ \\
\end{tabular}

Note: The values in the table represent mean \pm standard deviation. Different letters in the same column indicate significant differences

$(\mathrm{P}<0.05)$ as tested by using Duncan's new multiple range test. CD4-CD7: four treatment groups fed with an artificial diet with different enzyme activity in the larval midgut activity of digestive enzymes in the midgut of the fourth-instar larvae of S. litura were different. The relative amylase activity of the fourth-instar larvae fed with artificial diets with different bacterial loads was in the order $\mathrm{CD} 5>\mathrm{CD} 4>\mathrm{CD} 7>\mathrm{CD} 6>\mathrm{CK}$, and all groups that were fed with a feed supplemented with bacteria exhibited significantly higher activity than the control group. The relative trehalase activity of the fourth-instar larvae fed with artificial diets with different bacterial loads was in the order CD4 > CD5 > CD7 > CD6 > CK; except for the CD6 group, the other bacteria-fed groups 

those of the other groups.

S. litura fourth-instar larvae

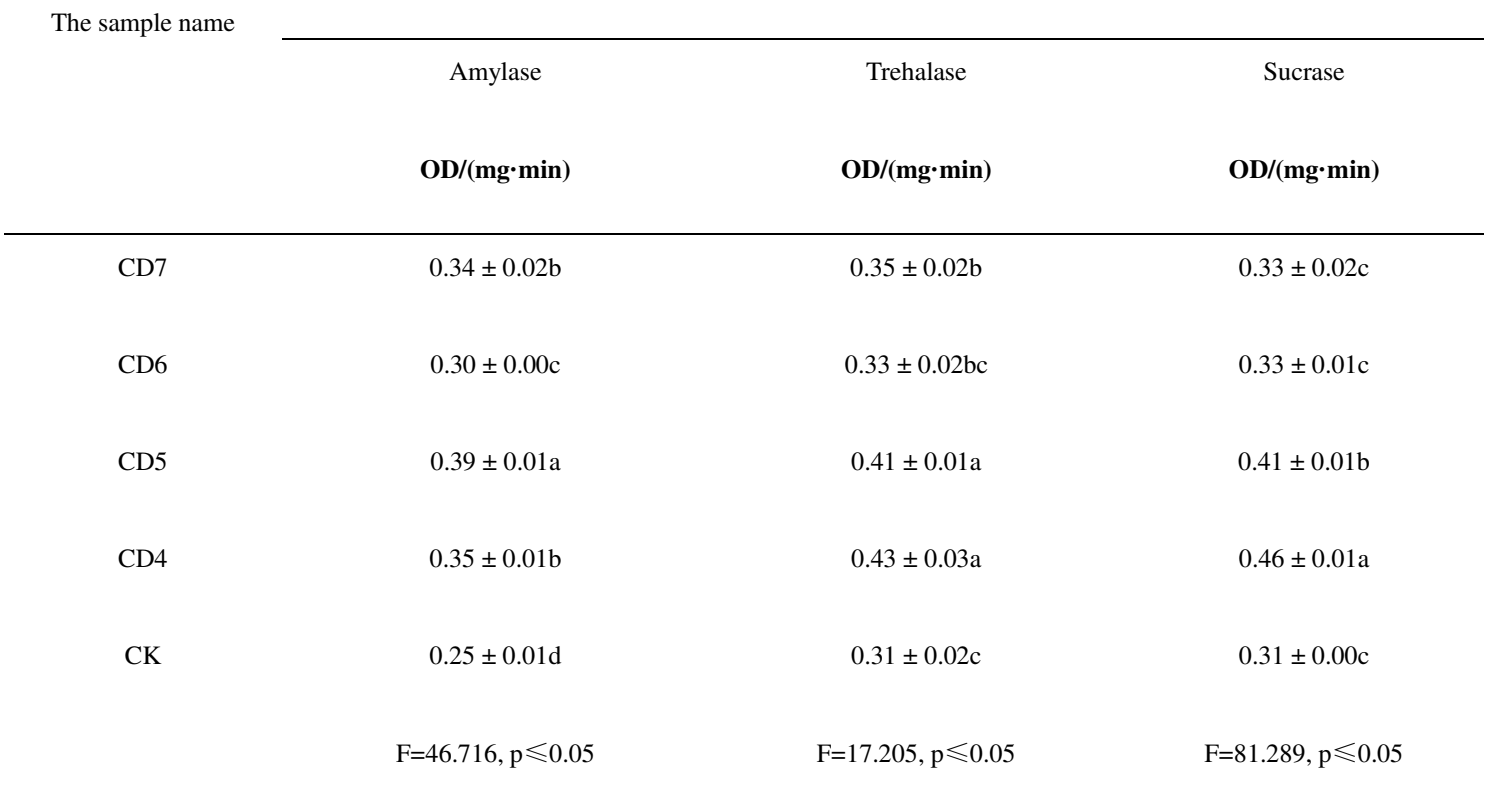

Note: The values in the table represent mean \pm standard deviation. Different letters in the same column indicate significant differences $(\mathrm{P}<0.05)$ as tested by using Duncan's new multiple range test. CD4-CD7: four treatment groups fed with an artificial diet with different bacterial loads; CK: control group.

\section{Effects of artificial diet with different bacterial loads exerted on pupae and} eggs of $S$. litura

As shown in Table 4, regarding the effect of artificial feeds with different bacterial loads exerted on the pupae of $S$. litura, the relative pupation rates of $S$. litura larval groups were in the order CD6 > CD7 > CD5 > CD4 > CK; the relative pupation rate of the CD6 group was significantly higher than 
1 that of the control group and there was no significant differences between the other groups. The relative

2

3

4 in the order $\mathrm{CD} 6>\mathrm{CD} 5>\mathrm{CK}>\mathrm{CD} 4>\mathrm{CD} 7$, and there were no significant differences between the groups. The relative male pupae weights were in the order CD6 > CD4 > CD5 > CK > CD7, and those of the CD6 and CD4 groups were significantly different from those of the control group. The relative pupal emergence rates were in the order CD6 > CK > CD5 > CD4 > CD7, and all larvae fed with

8 bacteria-supplemented diets exhibited significant differences compared with the control group. Regarding the effect of artificial feeds with different bacterial loads exerted on the eggs of S. litura, the relative number of eggs laid by a single female from each larval group was in the order CD6 > CD4 > CD5 > CD7 > CK, and values of the CD6 group were significantly higher than those of the control group. The relative egg hatching rates were in the order CD5 > CD6 > CK > CD4 > CD7, and, except for the CD6 group, the bacteria-fed groups were significantly different from the control group.

14 


\begin{tabular}{|c|c|c|c|c|c|c|c|}
\hline \multirow{2}{*}{$\begin{array}{c}\text { The sample } \\
\text { name }\end{array}$} & \multicolumn{5}{|c|}{ pupa } & \multicolumn{2}{|c|}{ egg } \\
\hline & $\begin{array}{l}\text { Pupation rate } \\
\text { (\%) }\end{array}$ & $\begin{array}{c}\text { Female/male } \\
\text { Sex ratio }\end{array}$ & $\begin{array}{l}\text { Female pupa } \\
\text { weight }(\mathrm{g})\end{array}$ & $\begin{array}{l}\text { Male pupal } \\
\text { weight }(\mathrm{g})\end{array}$ & $\begin{array}{c}\text { Pupa } \\
\text { emergence } \\
\text { rate }(\%)\end{array}$ & $\begin{array}{c}\text { Single female } \\
\text { spawn }\end{array}$ & $\begin{array}{c}\text { Egg hatching } \\
\text { rate }(\%)\end{array}$ \\
\hline CD7 & $\begin{array}{l}90.34 \pm \\
1.46 \mathrm{ab}\end{array}$ & $\begin{array}{l}0.87 \pm \\
0.06 \mathrm{bc}\end{array}$ & $0.31 \pm 0.03 \mathrm{a}$ & $0.26 \pm 0.01 \mathrm{c}$ & $56.76 \pm 2.71 \mathrm{~d}$ & $513.00 \pm 6.93 \mathrm{ab}$ & $69.15 \pm 2.02 \mathrm{c}$ \\
\hline CD6 & $92.74 \pm 1.47 \mathrm{a}$ & $\begin{array}{l}0.85 \pm \\
0.10 \mathrm{bc}\end{array}$ & $0.34 \pm 0.01 \mathrm{a}$ & $0.32 \pm 0.02 \mathrm{a}$ & $94.12 \pm 2.94 \mathrm{a}$ & $541.33 \pm 33.83 \mathrm{a}$ & $\begin{array}{l}81.37 \pm \\
1.01 \mathrm{ab}\end{array}$ \\
\hline CD5 & $\begin{array}{l}90.28 \pm \\
2.20 \mathrm{ab}\end{array}$ & $2.11 \pm 0.29 \mathrm{a}$ & $0.33 \pm 0.03 \mathrm{a}$ & $\begin{array}{l}0.30 \pm \\
0.01 \mathrm{ab}\end{array}$ & $62.50 \pm 1.79 \mathrm{c}$ & $\begin{array}{l}523.33 \pm \\
41.02 \mathrm{ab}\end{array}$ & $83.03 \pm 1.02 \mathrm{a}$ \\
\hline CD4 & $\begin{array}{l}90.02 \pm \\
1.51 \mathrm{ab}\end{array}$ & $0.69 \pm 0.05 c$ & $0.32 \pm 0.01 \mathrm{a}$ & $0.32 \pm 0.01 \mathrm{a}$ & $61.11 \pm 1.85 \mathrm{c}$ & $\begin{array}{l}524.33 \pm \\
55.58 \mathrm{ab}\end{array}$ & $70.92 \pm 1.88 \mathrm{c}$ \\
\hline CK & $\begin{array}{c}89.34 \pm \\
1.19 \mathrm{~b}\end{array}$ & $1.13 \pm 0.09 b$ & $0.33 \pm 0.01 \mathrm{a}$ & $\begin{array}{l}0.28 \pm \\
0.02 \mathrm{bc}\end{array}$ & $82.09 \pm 1.49 b$ & $478.00 \pm 38.20 \mathrm{~b}$ & $\begin{array}{l}79.41 \pm \\
0.79 b\end{array}$ \\
\hline & $\mathrm{F}=1.949$ & $\mathrm{~F}=46.663$ & $\mathrm{~F}=0.944$ & $\mathrm{~F}=13.700$ & $\mathrm{~F}=155.694$ & $\mathrm{~F}=2.480$ & $\mathrm{~F}=58.054$ \\
\hline & $p \leqslant 0.05$ & $p \leqslant 0.05$ & $\mathrm{p} \leqslant 0.05$ & $p \leqslant 0.05$ & $\mathrm{p} \leqslant 0.05$ & $p \leqslant 0.05$ & $\mathrm{p} \leqslant 0.05$ \\
\hline
\end{tabular}

$3(\mathrm{P}<0.05)$ as tested by using Duncan's new multiple range test. $\mathrm{CD} 4-\mathrm{CD} 7$ : four treatment groups fed with an artificial diet with different 
1 dominant populations of CD5 included Enterococcus (64.22\%), Ralstonia (26.75\%), and Weissella

2 (Collins et al., 1994) (4.04\%). The dominant populations of CD6 comprised Enterococcus (75.04\%),

3 Ralstonia (17.55\%), and Bacillus (Cohn, 1872) (4.58\%). The dominant populations of CD7 included

4 Enterococcus (91.68\%), Bacillus (3.97\%), and Rhodococcus (1.90\%). The dominant populations of CK

5 comprised Enterococcus (79.45\%), Weissella (15.99\%), and Rhodococcus (1.76\%). Compared with

6 CK, the dominant populations of bacteria changed from Weissella (Firmicutes) and Rhodococcus

7 (Firmicutes) to Ralstonia (Proteobacteria) and Bacillus (Firmicutes) (Fig. 1), and there was a negative

8 correlation between Enterococcus (Firmicutes) and Ralstonia (Proteobacteria).

9

10

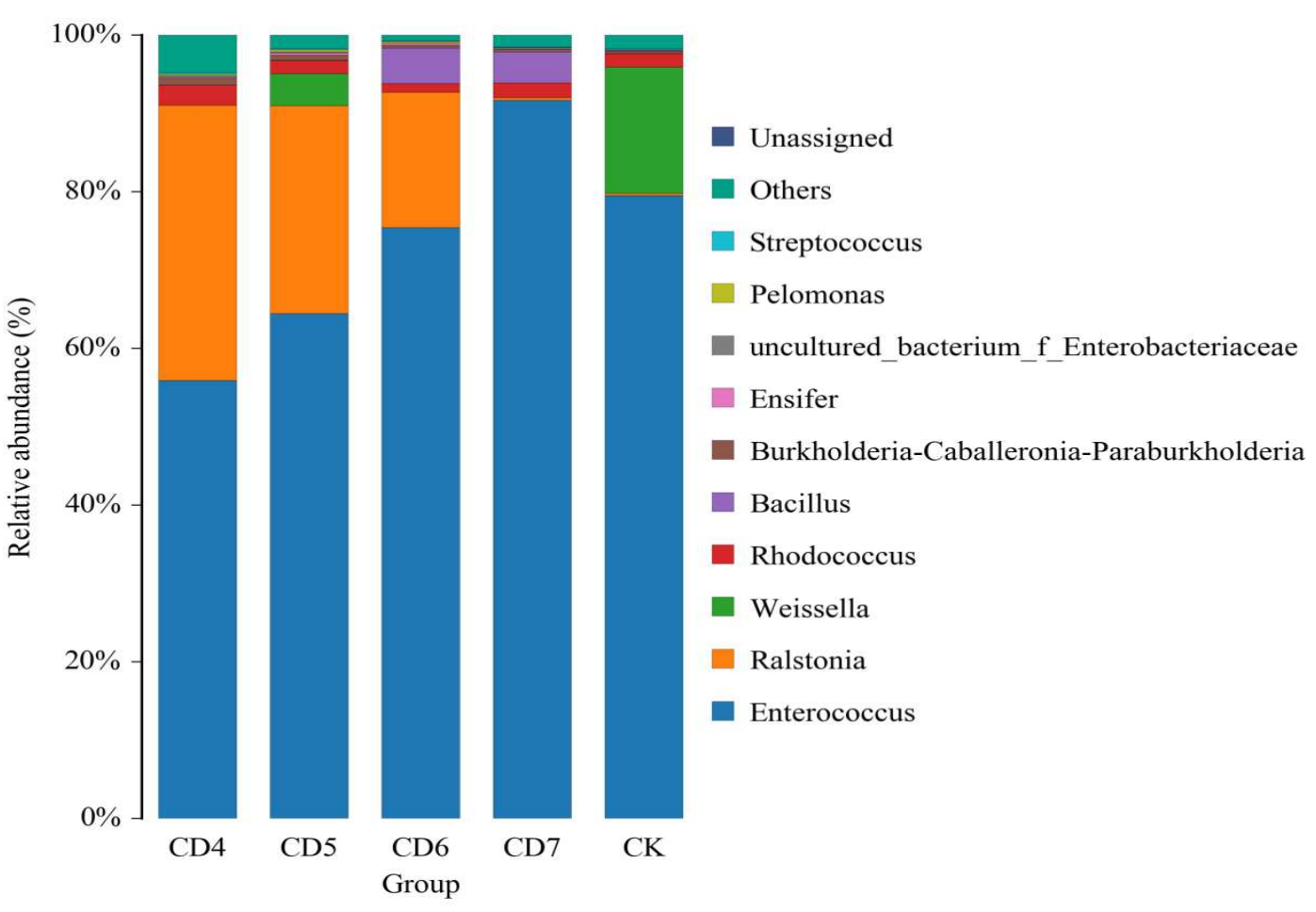

Fig. 1. Relative abundance of the detected gut bacteria at the genus level. The abscissa indicates the sample name; the ordinate indicates the relative abundance percentage. CD4-CD7: four treatment groups fed with an artificial diet with different bacterial loads; CK: control group. One color represents a species, and the length of the color block (bar graph) represents the relative abundance ratio of the species. 

all, but only 65 OTUs were shared by all of them (Fig. 2). Of these, one OTU was unique to CK, CD4, or $\mathrm{CD} 7$, and no OTU was unique to CD5 or CD6. A multi-sample comparison tree was constructed and

5 used to compare the community similarity of each sample at the OTU composition and phylogenetic

6 level. As illustrated by Fig. 1, the bacterial communities of CD4, CD5, and CD6 showed increased

7 similarity, and their phylogenetic distances were closer, compared with those of CK and CD7. Principal

8 component analysis (PCA) (Dubois 2010) can reflect the differences and distances of samples by analyzing the OTU composition of different samples. The closer the distance between two samples, the more similar is the composition of the two; therefore, the bacterial communities of the three treatment groups (CD4, CD5, and CD6) were similar, as they were clustered in the same area of the PCA (right or lower right) (Fig. 3). shown in Fig. 2. The top ten genera were distributed into three phyla and eight families. 


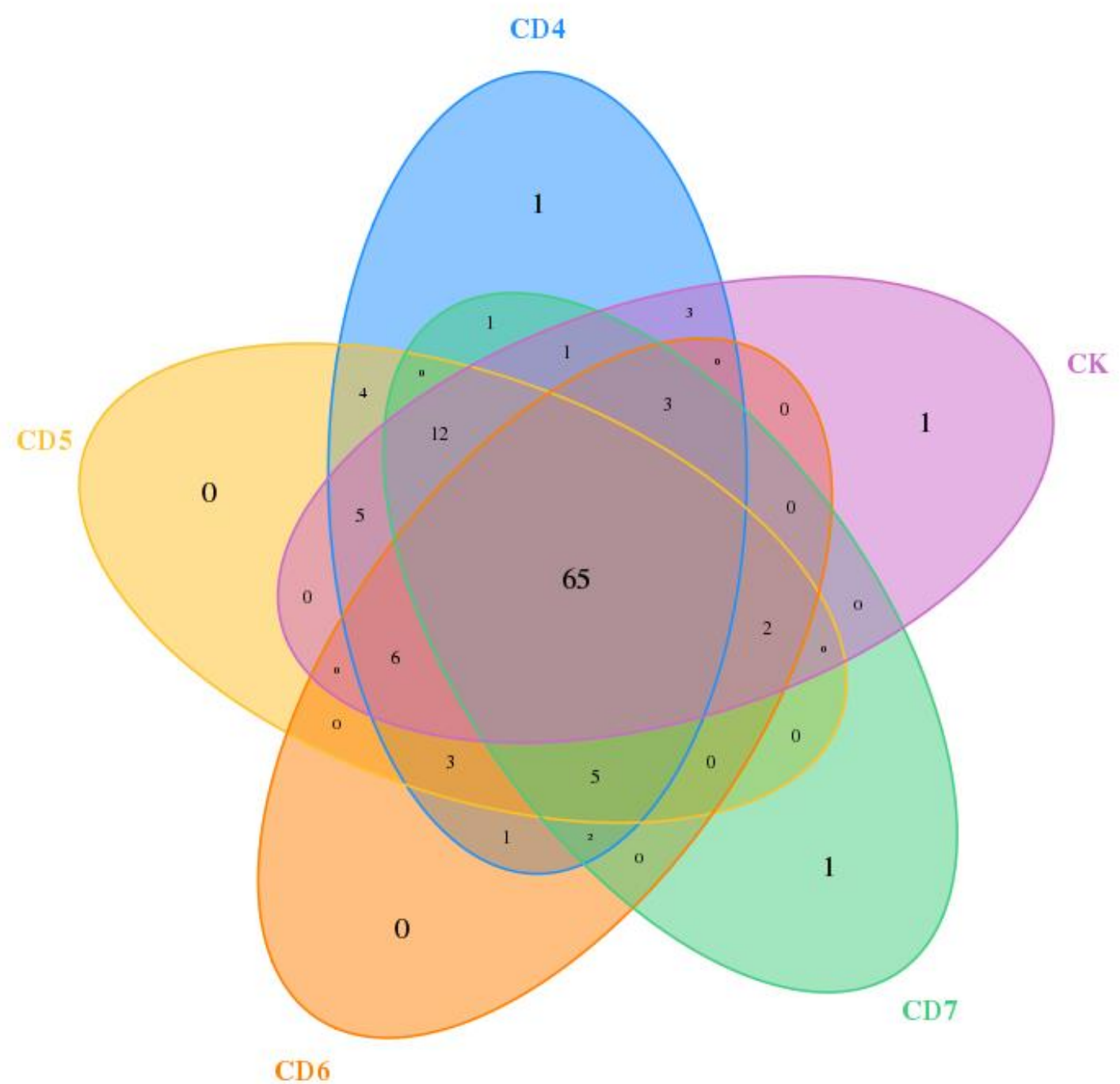

Fig. 2. Venn diagram of genus numbers among the control and four treatment groups in S. litura. CD4-CD7: four treatment groups fed

3 with an artificial diet with different bacterial loads; CK: control group. Different colors represent different samples. The number of overlapping sections between multiple color graphs indicate the number of OTUs among multiple samples, and the non-overlapping sections indicate the number of OTUs unique to each sample. Blue: CD4 treatment group; orange: CD5 treatment group; pink: CD6 treatment group; green: CD7 treatment group; purple: control group. 


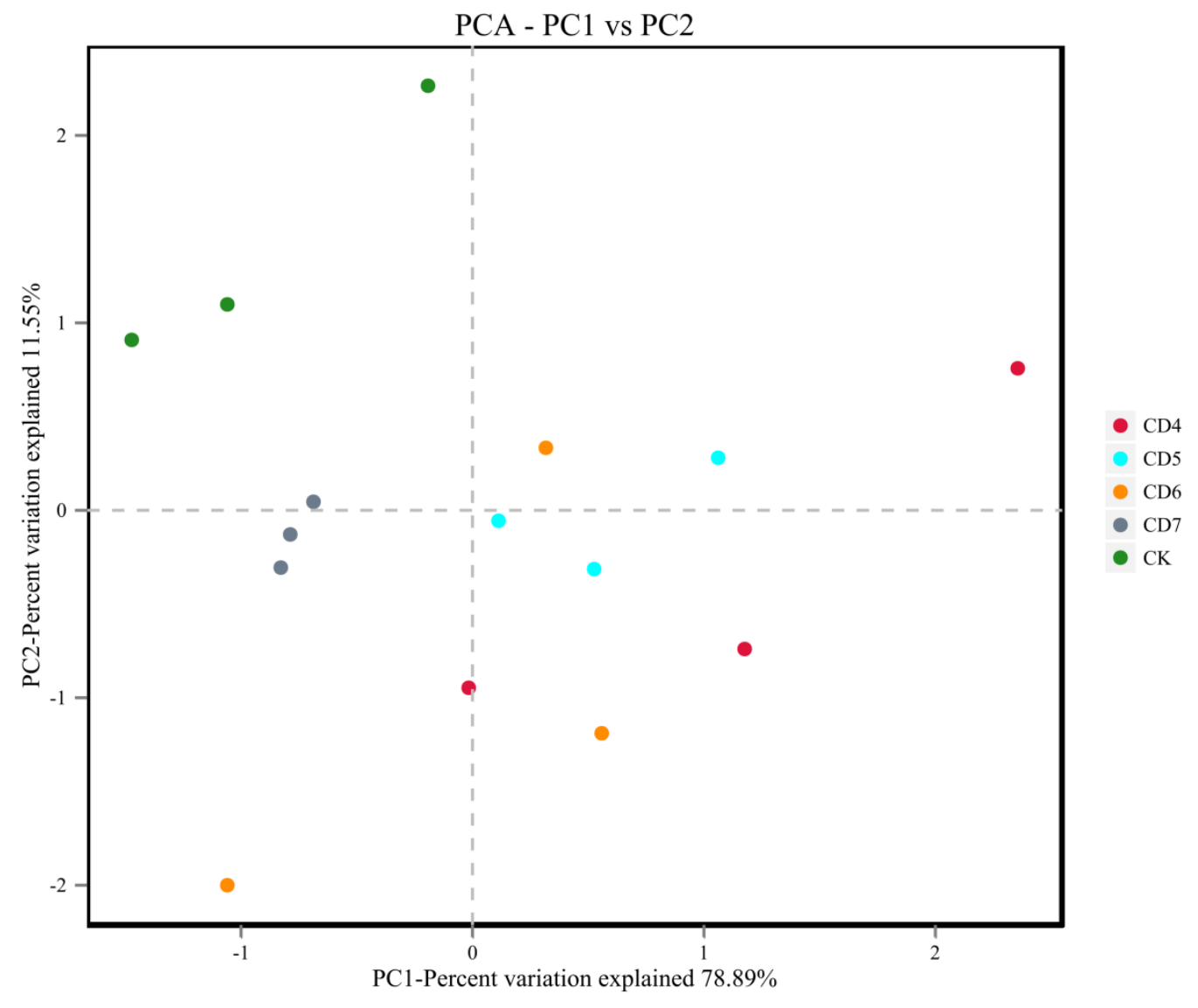

Fig. 3. Principal component analysis of gut bacteria diversity among the control and treatment groups. CD4-CD7: four treatment groups

5 component to the sample difference. The ordinate table indicates the second principal component, and the percentage indicates the contribution of the second principal component to the sample difference.

7 


\section{Discussion}

In biological research, microorganisms and other agents are often added to insect feed to conduct study on the effect of the added components on insect growth and development. Nutritional indices, such as food conversion rate and food utilization rate, reflect the degree of insect development to a certain extent, and they are mostly used to express the degree of preference and absorption of food by insects(Zhu et al. 2005a). The results showed that the relative growth rate, food conversion rate, and food utilization rate of larvae of the CD6 group were higher than those of the other treatment groups, indicating that the larvae of $S$. litura had higher adaptability to CD6. Although the food conversion rate and food utilization rate of the larvae of the CD5 and CD7 groups were higher than those of the control group, their relative growth rates and relative feeding rates were lower than those of the control group. Additionally, the relative feeding rate, food conversion rate, and food utilization rate of the larvae of the CD4 group were lower than those of the control group. This indicates that the three treatments using bacteria-supplemented feed, CD4, CD5, and CD7, are less suitable for application as feed for $S$. litura larvae. Moreover, the high feeding rate, food utilization rate, food conversion rate, and insect weight, along with low approximate digestibility, of the larvae of the CD6 indicate that certain substances in the artificial diet of the CD6 group could not be digested well by the larvae; however, substances that were digested resulted in higher food conversion and utilization rates, which could be better transformed into insect tissues (Zhigang et al. 2005).

Changes in the activities of digestive enzymes, such as sucrase and amylase, in insect intestines usually reflect the effect of food on insect host feeding and fitness to a certain extent ( Yuzhu et al. 2013). This study found that the larvae of the CD4 and CD5 groups had higher amylase, sucrase, and trehalase activities than the other groups, indicating the larvae in these two groups had relatively high 
1

2

conversion utilization of sugars, even though their growth rate was relatively low. Additionally, it was also determined that there was a significant positive correlation between the trehalase and sucrase activities of the larvae and the larval period of each treatment group, and the larvae feeding on these two groups of food did not show a high pupation rate, suggesting that this might be related to an imbalanced diet under high-carbohydrate nutritional conditions (MERKX-JACQUES et al. 2008). development rate, fecundity, and other aspects of growth and development (Jia, Y et al. 2012). The larvae of the CD6 group had relatively short larval period, which might be directly related to the diet fed during the larval stage. Additionally, the relatively high pupa weight of an insect further reflects its good developmental quality during the larval stage (Zhu et al. 2005b); furthermore, the larvae of the CD6 group did not exhibit a higher male to female ratio, which might be related to changes in the gut microbes. The present study found that the larvae of the CD5 group had a relatively high egg hatching rate, which might be related to its relatively high amylase activity and sugar conversion utilization rate.

Concurrently, the larvae of the CD7 group had relatively low pupal weights and egg hatching rates, which might be attributed to the poor development of the larvae and their relatively low utilization rate of sugar (Browne et al. 1993; Augner et al. 1995; Awmack et al. 2002).

The present study revealed that the addition of L. plantarum to the artificial diet of larvae altered their gut microbial flora composition as well as their abundance. After supplementing feed with L. plantarum, the growth of Weissella in the larval gut was inhibited to varying degrees, and to a certain extent, the growth of Ralstonia and Bacillus was promoted. Enterococcus (Lebreton et al. 2014; Vilanova et al. 2016), Weissella (Belda et al. 2011; Oh et al. 2013), and Ralstonia (Mohr et al. 2006; Anjum et al. 2018) have previously been reported as symbiotic bacteria in the gut. Similar to the 
1 findings presented in our study, Wang et al. (2018) documented variation in the diversity of gut microflora within piglets due to provision of feed supplemented with L. plantarum. Diet may affect the physical and chemical environment of the gut (Flint et al. 2008; Ley et al. 2008; Clissold et al. 2010; Sorensen et al. 2010), thereby limiting the types of bacterial strains that can survive in the gut ecosystem (Thakur et al. 2016).

The difference in growth and development of S. litura may also be attributed to the changes in gut microbial diversity (Thakur et al. 2016). LEfSe (Linear discriminant analysis effect size) analysis showed that the abundance of Ralstonia, Weissella, Bacillus, Enterococcus, and the unclassified genus significantly influenced the gut microbial community in the larvae (Fig. 4). This suggests their sensitivity to dietary administration and may help elucidate important physiological functions in the larvae (Zeng et al. 2020). The symbiotic gut bacterial community provides advantages to host insects via various mechanisms, such as involvement in the secretion of digestive enzymes, aiding survival with the best available diet, vitamin synthesis, improvement in digestion efficiency, and pathogen prevention (Berenbaum et al. 1988; Douglas et al. 1992; Behar et al. 2008; Osborne et al. 2009; Koch \& Schmid et al. 2011; Cheng et al. 2017; Al-Ghamdi et al. 2018); hence, they act as "microbial intermediaries" to compensate for the lack of certain biosynthetic and metabolic capabilities. Certain microorganisms may facilitate the production of digestive enzymes in certain insects (Terra et al. 1996). This study showed that after the larvae were fed with L. plantarum, the activity of digestive enzymes such as amylase also increased; however, the abundance of L. plantarum in the gut was less than $1 \%$, which might be related to a shorter colonization time in the gut. As the number of bacteria per unit of feed increased, the abundance of Ralstonia decreased, which was consistent with the trends of the enzyme activities, such as those of sucrase. Therefore, it is speculated that Ralstonia may participate in 
1 the induction of digestive enzymes.

\section{Cladogram}

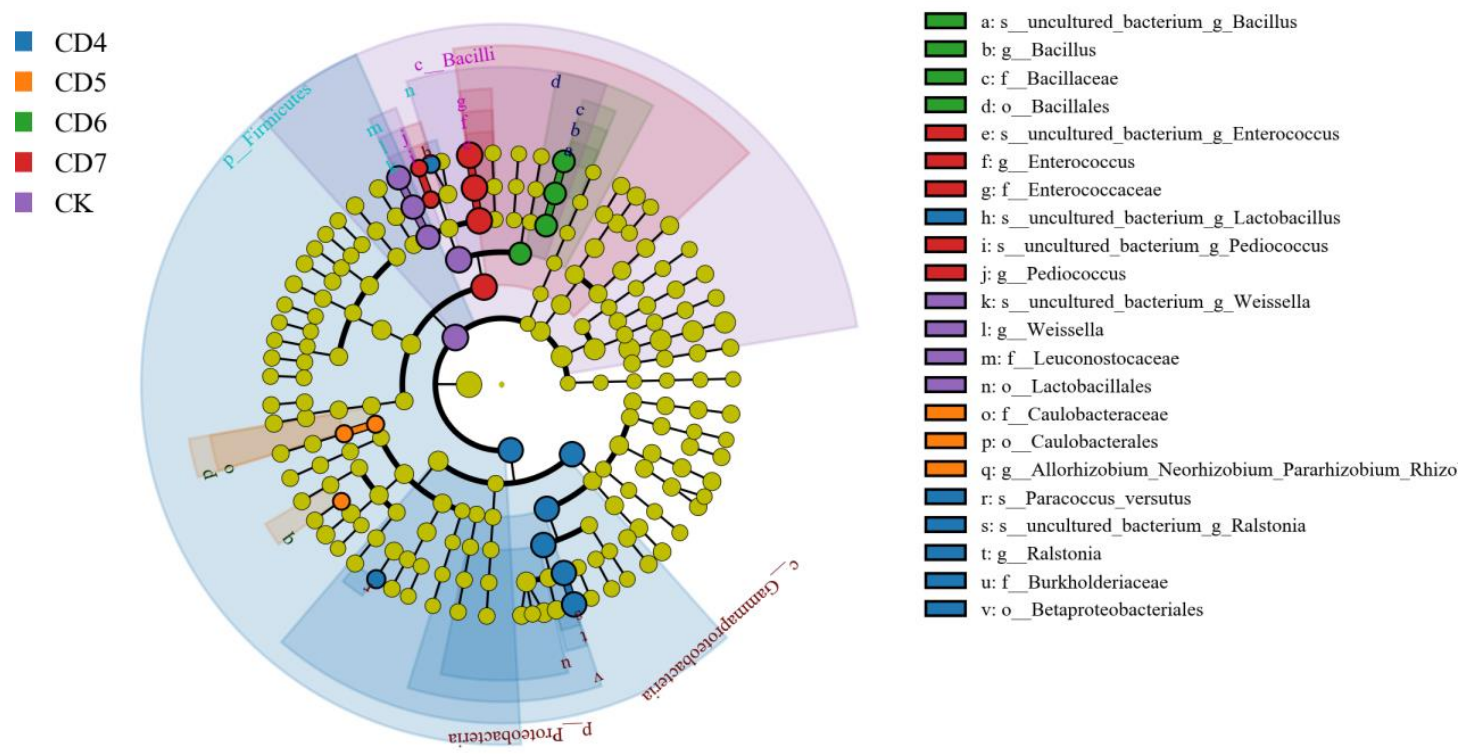

Fig. 4. Linear discriminant analysis effect size cladogram (LEfSe). CD4-CD7: four treatment groups fed with an artificial diet with

different bacterial loads; CK: control group. The circles radiating from the inside to the outside of the clade map represent the

However, certain gut microbes have also been reported as opportunistic pathogens, for example, 
1 effect on insect health in the digestive tract; however, they enter the insect hemolymph after the gut

2 periphagus is damaged, which adversely affects insect development (Bucher et al. 1963). After the $S$.

3

4

litura larvae were fed on L. plantarum, the growth of both microbes in the gut was inhibited to varying degrees, but the abundance of Enterococcus increased with an increase in the abundance of L. plantarum in the diet, and exceeded the Enterococcus abundance in the CK group when the abundance of L. plantarum in the diet was at its maximum, which might be attributed to the dynamic nature of the gut and its physical and chemical properties (Thakur et al. 2016).

In summary, addition of L. plantarum to an artificial diet can regulate the abundance and diversity of the gut microbes in S. litura larvae and affect their physiological functions. Furthermore, S. litura larvae fed with an artificial diet with different bacterial loads can develop and reproduce normally; however, the effects on the physiological development and intestinal microbes of S. litura are varied. The larvae of the CD6 group showed the best performance, with the feed promoting their physiological development. Additionally, the larvae of the CD4 and CD5 groups were significantly different with regard to pupae or adult male-female ratio compared with the control (the female-male ratios (female/male) were 0.69 and 2.11, respectively.). And the research found that after fed with a diet supplemented with L. plantarum, Faecalibaculum (Chang et al., 2016) in the intestine was significantly and positively correlated with the host female-male ratio $(\mathrm{p}<0.01)$. It is inferred that the change in host intestinal microbial abundance mediated by L. plantarum can induce a change in the host female-male ratio, which is similar to the results reported by Shan et al. (2019). Next, it is necessary to conduct related metabolomics analysis on the host female-male ratio changes and nutrient absorption mediated by probiotics based on existing judgments, in order to better explain this mediation mechanism, so as to achieve efficient management of economic pests; Therefore, the potential use of microorganisms to 
1 regulate the reproduction and development of insects further promotes the application of

2 microorganisms, especially probiotics, in laboratory insect breeding and the application of sterile insect

3 technique (SIT) in pest control (Augustinos et al. 2015). As a lactic acid bacterium isolated from the

4 gut cavity of $S$. litura larvae, L. plantarum presents with promising research and application prospects

5 in terms of laboratory insect feeding and biological control of diseases and insects (Ptaszyńska et al.

6 2016).

\section{Conclusion}

Feeding S. litura larvae with L. plantarum can effectively affect physiological and biochemical indicators, including host nutritional effect, digestive enzyme activity, and pupal weight, as well as exert a significant regulatory effect on the ratio of male to female adults. Additionally, changes in microbial abundance and diversity were found in the gut of $S$. litura larvae fed with diets supplemented with L. plantarum and without L. plantarum. Therefore, L. plantarum has potential applicability in pest management.

\footnotetext{
Abbreviations

L. Plantarum: Lactobacillus plantarum; S. litura: Spodoptera litura (Fabricius); CD4-CD7: four treatment groups fed with an artificial diet with different bacterial loads ; CK: control group ; PCA:

Principal Component Analysis ; LEfSe : Linear discriminant analysis effect size .
} 


\section{References}

Al-Ghamdi, A., Khan, K. A., Ansari, M. J., Almasaudi, S. B., \& Al-Kahtani, S. (2018). Effect of gut bacterial isolates from Apis mellifera jemenitica on Paenibacillus larvae infected bee larvae. Saudi journal of biological sciences, 25(2), 383-387.

Anjum, S. I., Shah, A. H., Aurongzeb, M., Kori, J., Azim, M. K., Ansari, M. J., \& Bin, L. (2018). Characterization of gut bacterial flora of Apis mellifera from north-west Pakistan. Saudi journal of biological sciences, 25(2), 388-392.

Augner, M. (1995). Low nutritive quality as a plant defence: effects of herbivore-mediated interactions. Evolutionary Ecology, 9(6), 605-616.

Augustinos, A. A., Kyritsis, G. A., Papadopoulos, N. T., Abd-Alla, A. M., Cáceres, C., \& Bourtzis, K. (2015). Exploitation of the medfly gut microbiota for the enhancement of sterile insect technique: use of Enterobacter sp. in larval diet-based probiotic applications. PLoS One, 10(9), e0136459.

Awmack, C. S., \& Leather, S. R. (2002). Host plant quality and fecundity in herbivorous insects. Annual review of entomology, 47(1), 817-844.

Behar, A., Yuval, B., \& Jurkevitch, E. (2008). Gut bacterial communities in the Mediterranean fruit fly (Ceratitis capitata) and their impact on host longevity. Journal of Insect Physiology, 54(9), 1377-1383.

Belda, E., Pedrola, L., Peretó, J., Martínez-Blanch, J. F., Montagud, A., Navarro, E., ... \& Porcar, M. (2011). Microbial diversity in the midguts of field and lab-reared populations of 
Browne, L. B. (1993). Physiologically induced changes in resource-oriented behavior. Annual Review of Entomology, 38(1), 1-23.

Bucher, G. E. (1963). Nonsporulating bacterial pathogens. In Insect pathology (pp. 117-147). Academic Press.

Cheng, D., Guo, Z., Riegler, M., Xi, Z., Liang, G., \& Xu, Y. (2017). Gut symbiont enhances insecticide resistance in a significant pest, the oriental fruit fly Bactrocera dorsalis (Hendel). Microbiome, 5(1), 13.

Clissold, F. J., Tedder, B. J., Conigrave, A. D., \& Simpson, S. J. (2010). The gastrointestinal tract as a nutrient-balancing organ. Proceedings of the Royal Society B: Biological Sciences, 277(1688), 1751-1759.

Crawford, J. E., Clarke, D. W., Criswell, V., Desnoyer, M., Cornel, D., Deegan, B., ... \& White, B. J. (2020). Efficient production of male Wolbachia-infected Aedes aegypti mosquitoes enables large-scale suppression of wild populations. Nature biotechnology, 38(4), $482-492$.

Dillon, R., \& Charnley, K. (2002). Mutualism between the desert locust Schistocerca gregaria and its gut microbiota. Research in microbiology, 153(8), 503-509.

Douglas, A. E. (1992). Microbial brokers of insect-plant interactions. In Proceedings of the 8th International Symposium on Insect-Plant Relationships (pp. 329-336). Springer, Dordrecht.

Dubois, P. C., Trynka, G., Franke, L., Hunt, K. A., Romanos, J., Curtotti, A., ... \& Bardella, 

M. T. (2010). Multiple common variants for celiac disease influencing immune gene expression. Nature genetics, 42(4), 295-302.

Evans, J. D., \& Armstrong, T. N. (2006). Antagonistic interactions between honey bee bacterial symbionts and implications for disease. BMC ecology, 6(1), 1-9.

Fisher, K., \& Phillips, C. (2009). The ecology, epidemiology and virulence of Enterococcus. Microbiology, 155(6), 1749-1757. 
2 Heckel, D. G. (2020). How do toxins from Bacillus thuringiensis kill insects? An evolutionary perspective. Archives of insect biochemistry and physiology, 104(2), e21673.

Hedges, L. M., Brownlie, J. C., O'Neill, S. L., \& Johnson, K. N. (2008). Wolbachia and virus protection in insects. Science, 322(5902), 702-702.

Jia, Y., Cheng, X., Cai, Y., Luo, M., Guo, X., \& Yuan, G. (2012). Difference of the fitness of Helicoverpa armigera(Huebner) fed with different pepper varieties. Shengtai Xuebao/Acta Ecologica Sinica, 32(1), 159-167.

Kikuchi, Y., Hosokawa, T., \& Fukatsu, T. (2011). An ancient but promiscuous host-symbiont association between Burkholderia gut symbionts and their heteropteran hosts. The ISME journal, 5(3), 446-460.

Kikuchi, Y., Hayatsu, M., Hosokawa, T., Nagayama, A., Tago, K., \& Fukatsu, T. (2012). Symbiont-mediated insecticide resistance. Proceedings of the National Academy of Sciences, 109(22), 8618-8622.

Koch, H., \& Schmid-Hempel, P. (2011). Socially transmitted gut microbiota protect bumble bees against an intestinal parasite. Proceedings of the National Academy of Sciences, 108(48), 19288-19292.

Lebreton, F., Willems, R. J., \& Gilmore, M. S. (2014). Enterococcus diversity, origins in nature, and gut colonization. In Enterococci: from commensals to leading causes of drug resistant infection [Internet]. Massachusetts Eye and Ear Infirmary. 
Ley, R. E., Lozupone, C. A., Hamady, M., Knight, R., \& Gordon, J. I. (2008). Worlds within worlds: evolution of the vertebrate gut microbiota. Nature Reviews Microbiology, 6(10), 776-788.

Li, Y. H., Huang, Y. F., Chen, T. H., Wu, S. S., Tang, H. C., Hsiao, C. Y., ... \& Nai, Y. S. (2020). Comparison of gut microbiota of healthy and diseased walking sticks, Phasmotaenia lanyuhensis. Archives of Insect Biochemistry and Physiology, 105(4), e21749.

Luan Yuzhu, Gu Jiwei \& Li Meiling. (2013). The effect of different host plants on S. litura and its mechanism. Jiangsu Agricultural Sciences (11), 142-144 ( In Chinese).

MERKX-JACQUES, M. A. G. A. L. I., Despland, E., \& Bede, J. C. (2008). Nutrient utilization by caterpillars of the generalist beet armyworm, Spodoptera exigua. Physiological Entomology, 33(1), 51-61.

Mkiga, A. M., Mohamed, S. A., du Plessis, H., Khamis, F. M., Akutse, K. S., \& Ekesi, S. (2020). Metarhizium anisopliae and Beauveria bassiana: pathogenicity, horizontal transmission, and their effects on reproductive potential of Thaumatotibia leucotreta (Lepidoptera: Tortricidae). Journal of economic entomology, 113(2), 660-668.

Mohr, K. I., \& Tebbe, C. C. (2006). Diversity and phylotype consistency of bacteria in the guts of three bee species (Apoidea) at an oilseed rape field. Environmental Microbiology, 8(2), 258-272.

Oh, S. J., Shin, N. R., Hyun, D. W., Kim, P. S., Kim, J. Y., Kim, M. S., ... \& Bae, J. W. (2013). Weisselladiestrammenae sp. nov., isolated from the gut of a camel cricket (Diestrammena 
coreana). International journal of systematic and evolutionary microbiology, 63(8), 2951-2956.

Osborne, S. E., San Leong, Y., O'Neill, S. L., \& Johnson, K. N. (2009). Variation in antiviral protection mediated by different Wolbachia strains in Drosophila simulans. PLoS Pathog, 5(11), e1000656.

Paniagua Voirol, L. R., Frago, E., Kaltenpoth, M., Hilker, M., \& Fatouros, N. E. (2018). Bacterial symbionts in Lepidoptera: their diversity, transmission, and impact on the host. Frontiers in microbiology, 9, 556.

Poinsot, D., Charlat, S., \& Mercot, H. (2003). On the mechanism of Wolbachia-induced cytoplasmic incompatibility: Confronting the models with the facts. Bioessays, 25(3), 259-265.

Ptaszyńska, A. A., Borsuk, G., Zdybicka-Barabas, A., Cytryńska, M., \& Małek, W. (2016). Are commercial probiotics and prebiotics effective in the treatment and prevention of honeybee nosemosis C?. Parasitology research, 115(1), 397-406.

Shan, H. W., Luan, J. B., Liu, Y. Q., Douglas, A. E., \& Liu, S. S. (2019). The inherited bacterial symbiont Hamiltonella influences the sex ratio of an insect host. Proceedings of the Royal Society B, 286(1915), 20191677.

Sørensen, A., Mayntz, D., Simpson, S. J., \& Raubenheimer, D. (2010). Dietary ratio of protein to carbohydrate induces plastic responses in the gastrointestinal tract of mice. Journal of Comparative Physiology B, 180(2), 259-266. 
1 Teixeira, L., Ferreira, Á., \& Ashburner, M. (2008). The bacterial symbiont Wolbachia induces resistance to RNA viral infections in Drosophila melanogaster. PLoS Biol, 6(12), e1000002.

Terra, W. R., Ferreira, C., Jordao, B. P., \& Dillon, R. J. (1996). Digestive enzymes. In Biology of the insect midgut (pp. 153-194). Springer, Dordrecht.

Thakur, A., Dhammi, P., Saini, H. S., \& Kaur, S. (2016). Effect of antibiotic on survival and development of S. litura (Lepidoptera: Noctuidae) and its gut microbial diversity. Bulletin of Entomological Research, 106(3), 387.

Vilanova, C., Baixeras, J., Latorre, A., \& Porcar, M. (2016). The generalist inside the specialist: gut bacterial communities of two insect species feeding on toxic plants are dominated by Enterococcus sp. Frontiers in microbiology, 7, 1005.

Wang G H, Zhao Q J, Xu F D, et al. Influence of three kinds of plant leaves on Prodenia litura nutrient effect and intestinal enzyme activity[J]. Guizhou Agricultural Sciences, 2016, 44(2): $77-80$

Wheeler, D. A., \& Isman, M. B. (2001). Antifeedant and toxic activity of Trichilia americana extract against the larvae of S. litura . Entomologia Experimentalis et Applicata, 98(1), 9-16.

Yin, Y., Mu, D., Chen, S., Liu, L., \& Wang, Z. (2011). The title of the article: effects on growth and digestive enzyme activities of the Hepialus gonggaensis larvae caused by introducing probiotics. World Journal of Microbiology and Biotechnology, 27(3), 529-533.

Zeng, J. Y., Wu, D. D., Shi, Z. B., Yang, J., Zhang, G. C., \& Zhang, J. (2020). Influence of dietary aconitine and nicotine on the gut microbiota of two lepidopteran herbivores. Archives 
2

3

\section{Zhigang, L., Shichou, H. A. N., Mingfang, G., Liying, L., Tongxu, P., Wenhui, L., \& Lifen, L.} (2005). Effects of feeding on different food plants on nutritional utilization and midgut enzyme activities in $\{\backslash$ sl Actinote anteas\}(Lepidoptera: Nymphalidae). Kun Chong xue bao. Acta Entomologica Sinica, 48(5), 674-678.

Zhu, L. M., Ni, Y. P., Cao, X. Y., Huang, C. X., \& Cui, Q. (2001). A method for artificially rearing to the cotton leafworm Prodenia litura Fabricius. Entomol Knowl, 38, 227-228.

Zhu, J. H., Zhang, F. P. (2005a). Preliminary report on the occurrence and damage of Prodenia litura in banana gardens. Fruit trees in South China (01), 32 (In Chinese).

Zhu, J. H., Zhang, F. P., \& Ren, H. G. (2005b). Development and nutrition of Prodenia litura on four food plants. China Bulletin of Entomology, 42, 643-646. 


\section{Figures}

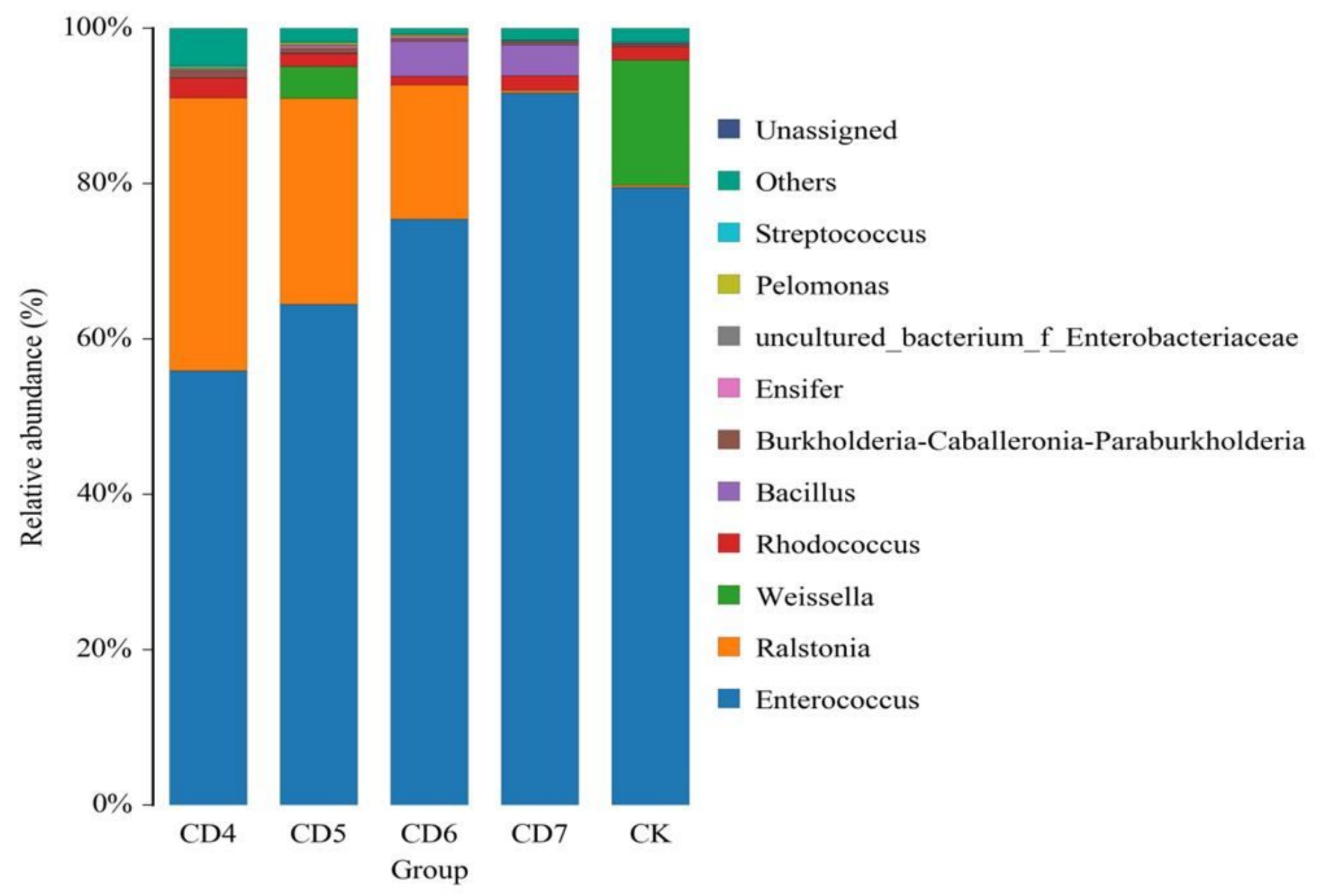

\section{Figure 1}

Relative abundance of the detected gut bacteria at the genus level. The abscissa indicates the sample name; the ordinate indicates the relative abundance percentage. CD4-CD7: four treatment groups fed with an artificial diet with different bacterial loads; CK: control group. One color represents a species, and the length of the color block (bar graph) represents the relative abundance ratio of the species. 


\section{CD4}

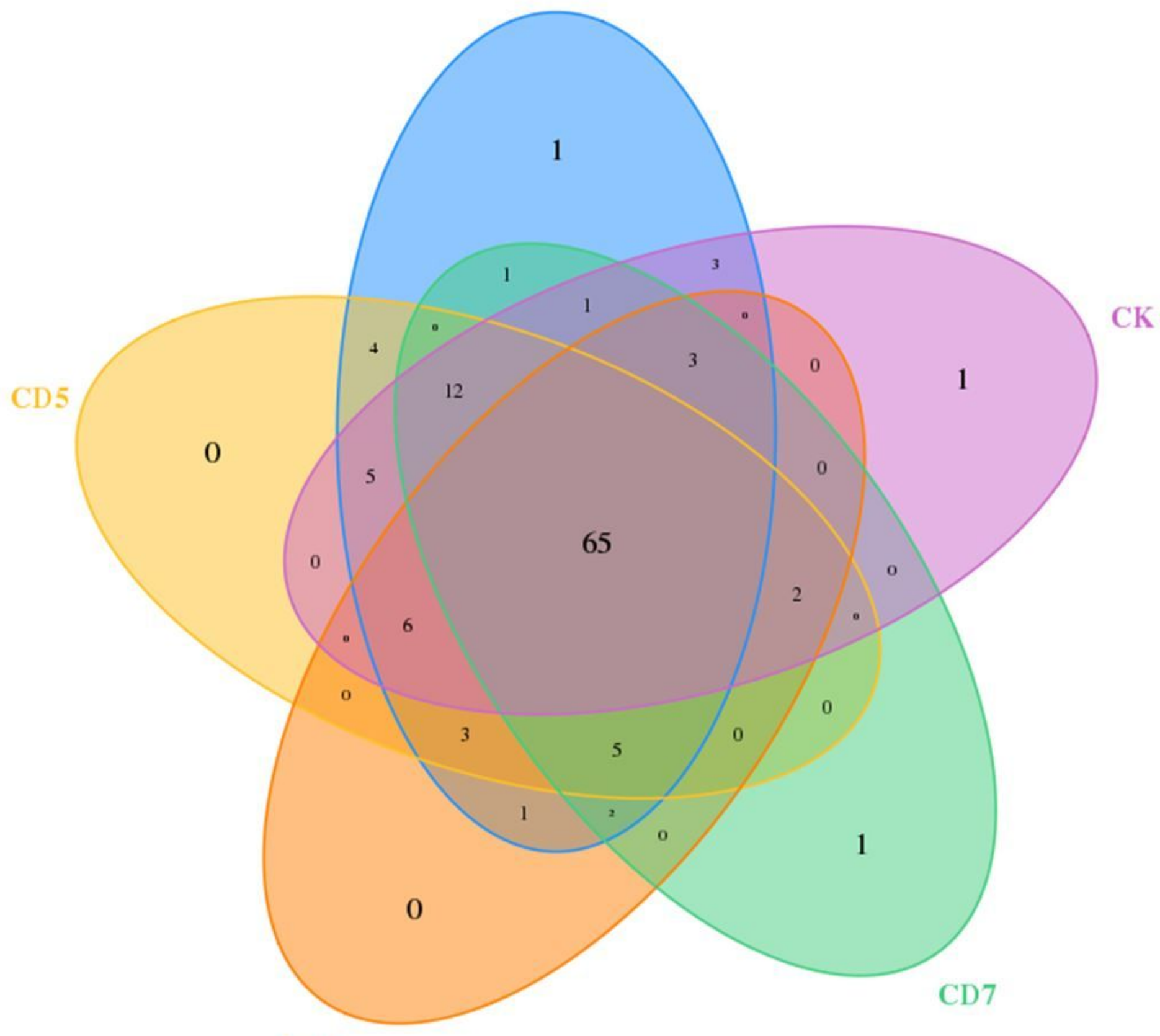

\section{CD6}

\section{Figure 2}

Venn diagram of genus numbers among the control and four treatment groups in S. litura. CD4-CD7: four treatment groups fed with an artificial diet with different bacterial loads; CK: control group. Different colors represent different samples. The number of overlapping sections between multiple color graphs indicate the number of OTUs among multiple samples, and the non-overlapping sections indicate the number of OTUs unique to each sample. Blue: CD4 treatment group; orange: CD5 treatment group; pink: CD6 treatment group; green: CD7 treatment group; purple: control group. 
PCA - PC1 vs PC2

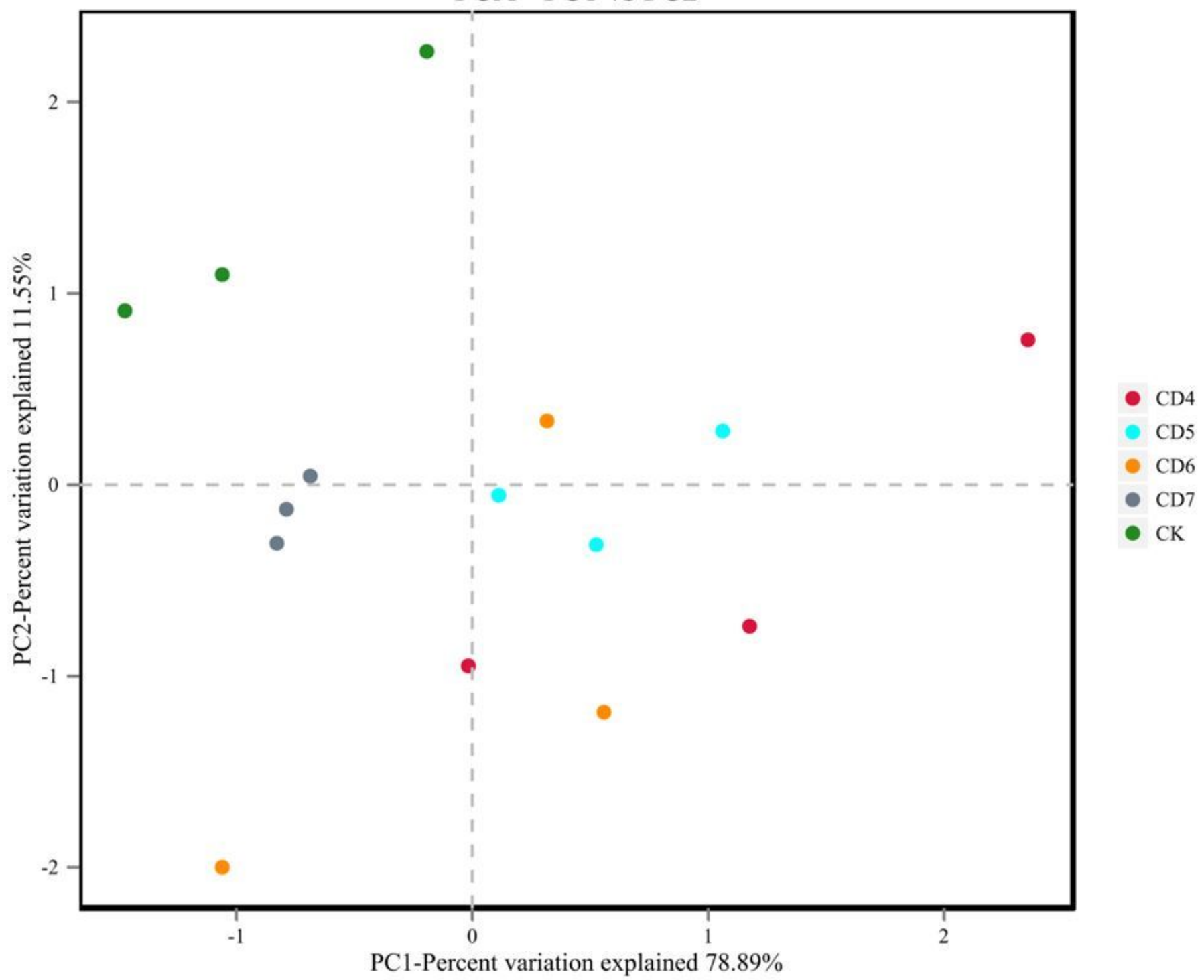

\section{Figure 3}

Principal component analysis of gut bacteria diversity among the control and treatment groups. CD4-CD7: four treatment groups fed with an artificial diet with different bacterial loads; CK: control group. The dots represent each sample and different colors represent different groups. The abscissa represents the first principal component, and the percentage represents the contribution of the first principal component to the sample difference. The ordinate table indicates the second principal component, and the percentage indicates the contribution of the second principal component to the sample difference. 


\section{Cladogram}

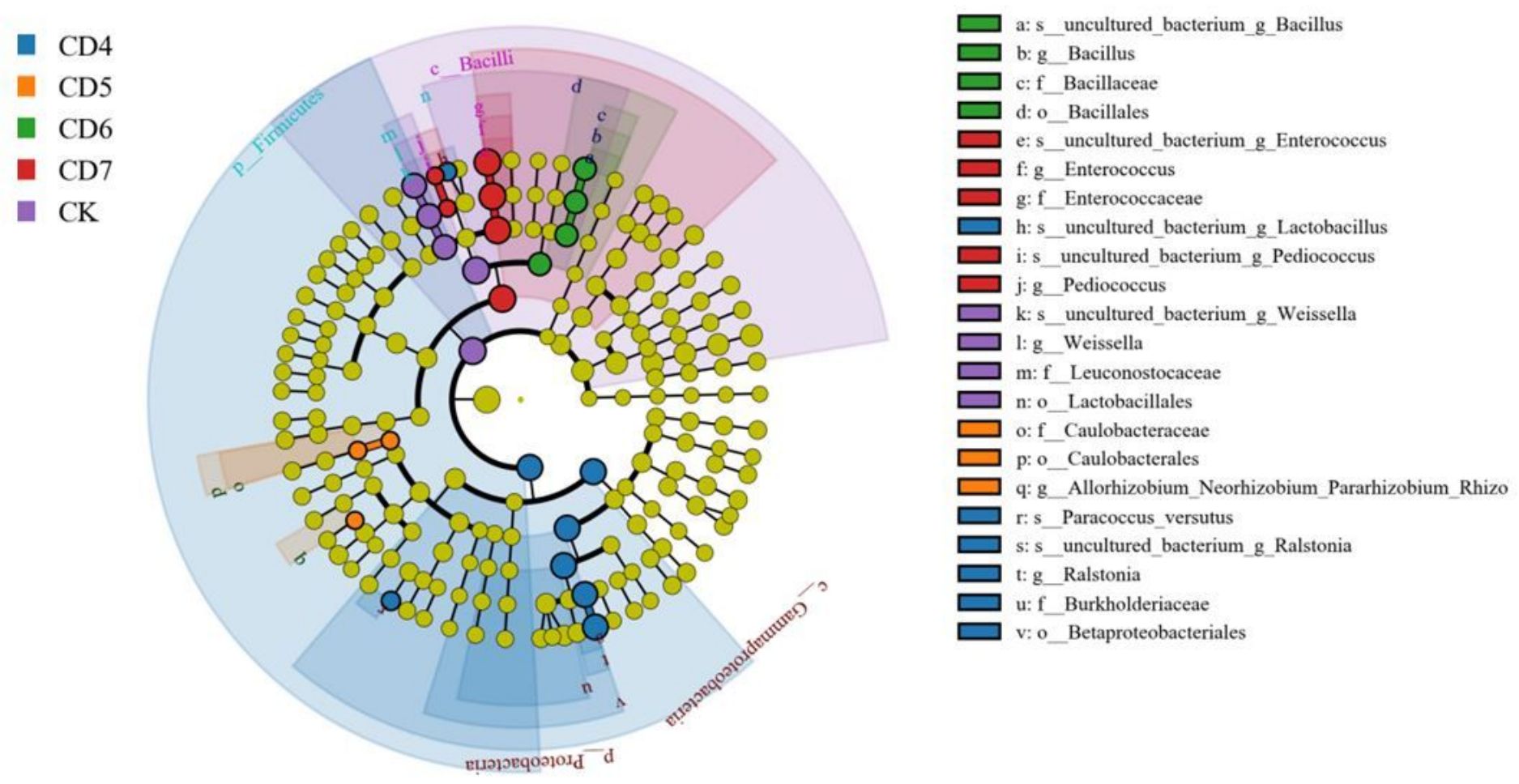

Figure 4

Linear discriminant analysis effect size cladogram (LEfSe). CD4-CD7: four treatment groups fed with an artificial diet with different bacterial loads; CK: control group. The circles radiating from the inside to the outside of the clade map represent the classification level from phylum to species. Each small circle at different classification levels represents a classification at that level, and the diameter of the small circle is proportional to the relative abundance. The coloring principle includes the uniform coloration of the species name, with no significant differences highlighted in yellow, and other different species are colored according to the group with the highest abundance of the species. Different colors indicate different groups, and nodes of different colors indicate the microbial groups that play an important role in the group represented by the color. 